\title{
"Having All of Your Internal Resources Exhausted Beyond Measure and Being Left with No Clean-Up Crew": Defining Autistic Burnout
}

\author{
Dora M. Raymaker, PhD, ${ }^{1,2}$ Alan R. Teo, MD, MS, ${ }^{3-5}$ Nicole A. Steckler, PhD, ${ }^{6}$ Brandy Lentz, \\ Mirah Scharer, BS, ${ }^{1}$ Austin Delos Santos, ${ }^{1}$ Steven K. Kapp, PhD, ${ }^{2,7}$ Morrigan Hunter, MA, ${ }^{2}$ \\ Andee Joyce, $\mathrm{BA}^{2}{ }^{2}$ and Christina Nicolaidis, $\mathrm{MD}, \mathrm{MPH}^{1,2,5,8}$
}

\begin{abstract}
Background: Although autistic adults often discuss experiencing "autistic burnout" and attribute serious negative outcomes to it, the concept is almost completely absent from the academic and clinical literature.

Methods: We used a community-based participatory research approach to conduct a thematic analysis of 19 interviews and 19 public Internet sources to understand and characterize autistic burnout. Interview participants were autistic adults who identified as having been professionally diagnosed with an autism spectrum condition. We conducted a thematic analysis, using a hybrid inductive-deductive approach, at semantic and latent levels, through a critical paradigm. We addressed trustworthiness through multiple coders, peer debriefing, and examination of contradictions.

Results: Autistic adults described the primary characteristics of autistic burnout as chronic exhaustion, loss of skills, and reduced tolerance to stimulus. They described burnout as happening because of life stressors that added to the cumulative load they experienced, and barriers to support that created an inability to obtain relief from the load. These pressures caused expectations to outweigh abilities resulting in autistic burnout. Autistic adults described negative impacts on their health, capacity for independent living, and quality of life, including suicidal behavior. They also discussed a lack of empathy from neurotypical people and described acceptance and social support, time off/reduced expectations, and doing things in an autistic way/unmasking as associated in their experiences with recovery from autistic burnout.

Conclusions: Autistic burnout appears to be a phenomenon distinct from occupational burnout or clinical depression. Better understanding autistic burnout could lead to ways to recognize, relieve, or prevent it, including highlighting the potential dangers of teaching autistic people to mask or camouflage their autistic traits, and including burnout education in suicide prevention programs. These findings highlight the need to reduce discrimination and stigma related to autism and disability.
\end{abstract}

Keywords: autism, burnout, autistic burnout, community-based participatory research

${ }^{1}$ Regional Research Institute, School of Social Work, Portland State University, Portland, Oregon, USA.

${ }^{2}$ Academic Autism Spectrum Partnership in Research and Education, Portland, Oregon, USA.

${ }^{3}$ VA Portland Health Care System, HSR\&D Center to Improve Veteran Involvement in Care (CIVIC), Portland, Oregon, USA.

${ }^{4}$ Department of Psychiatry, Oregon Health \& Science University, Portland, Oregon, USA.

${ }^{5}$ School of Public Health, Oregon Health \& Science University and Portland State University, Portland, Oregon, USA.

${ }^{6}$ Division of Management, School of Medicine, Oregon Health \& Science University, Portland, Oregon, USA.

${ }^{7}$ Department of Psychology, University of Portsmouth, Portsmouth, United Kingdom.

${ }^{8}$ Department of Medicine, Oregon Health \& Science University, Portland, Oregon, USA.

(C) Dora M. Raymaker, et al, 2020; Published by Mary Ann Liebert, Inc. This Open Access article is distributed under the terms of the Creative Commons Attribution Noncommercial License (http://creativecommons.org/licenses/by-nc/4.0/) which permits any noncommercial use, distribution, and reproduction in any medium, provided the original author(s) and the source are cited 


\section{Lay Summary}

Why was this study done?

Autistic burnout is talked about a lot by autistic people but has not been formally addressed by researchers. It is an important issue for the autistic community because it is described as leading to distress; loss of work, school, health, and quality of life; and even suicidal behavior.

What was the purpose of this study?

This study aimed to characterize autistic burnout, understand what it is like, what people think causes it, and what helps people recover from or prevent it. It is a first step in starting to understand autistic burnout well enough to address it.

\section{What did the researchers do?}

Our research group - the Academic Autism Spectrum Partnership in Research and Education-used a community-based participatory research approach with the autistic community in all stages of the study. We analyzed 9 interviews from our study on employment, 10 interviews about autistic burnout, and 19 public Internet sources (five in-depth). We recruited in the United States by publicizing on social media, by word of mouth, and through community connections. When analyzing interviews, we took what people said at face value and in deeper social context, and looked for strong themes across data.

\section{What were the results of the study?}

The primary characteristics of autistic burnout were chronic exhaustion, loss of skills, and reduced tolerance to stimulus. Participants described burnout as happening because of life stressors that added to the cumulative load they experienced, and barriers to support that created an inability to obtain relief from the load. These pressures caused expectations to outweigh abilities resulting in autistic burnout. From this we created a definition:

Autistic burnout is a syndrome conceptualized as resulting from chronic life stress and a mismatch of expectations and abilities without adequate supports. It is characterized by pervasive, long-term (typically $3+$ months) exhaustion, loss of function, and reduced tolerance to stimulus.

Participants described negative impacts on their lives, including health, capacity for independent living, and quality of life, including suicidal behavior. They also discussed a lack of empathy from neurotypical people. People had ideas for recovering from autistic burnout including acceptance and social support, time off/reduced expectations, and doing things in an autistic way/unmasking.

How do these findings add to what was already known?

We now have data that autistic burnout refers to a clear set of characteristics, and is different from workplace burnout and clinical depression. We have the start of a model for why autistic burnout might happen. We know that people have been able to recover from autistic burnout and have some insights into how.

What are the potential weaknesses in the study?

This was a small exploratory study with a convenience sample. Although we were able to bring in some diversity by using three data sources, future work would benefit from interviewing a wider range of participants, especially those who are not white, have higher support needs, and have either very high or very low educational attainment. More research is needed to understand how to measure, prevent, and treat autistic burnout.

\section{How will these findings help autistic adults now or in the future?}

These findings validate the experience of autistic adults. Understanding autistic burnout could lead to ways to help relieve it or prevent it. The findings may help therapists and other practitioners recognize autistic burnout, and the potential dangers of teaching autistic people to mask autistic traits. Suicide prevention programs should consider the potential role of burnout. These findings highlight the need to reduce discrimination and stigma around autism and disability. 


\section{Introduction}

" Utistic Burnout" Is often used by autistic adults to describe a state of incapacitation, exhaustion, and distress in every area of life. ${ }^{1}$ Informally, autistic adults describe how burnout has cost them jobs, friends, activities, independence, mental and physical health, and pushed them to suicidal behavior. ${ }^{1,2}$ The Twitter hashtag \#AutisticBurnout produces hundreds of urgent messages among autistic people trying to understand, prevent, or recover from autistic burnout. Addressing autistic burnout is a high priority for autistic adults. ${ }^{1,2}$

Despite how often and urgently the autistic community discusses autistic burnout, the concept is almost completely absent from the academic and clinical literature. A literature search for autism and burnout produces publications on family, teacher, caregiver, peer, and other burnout related to caring for or being around autistic people, ${ }^{3-6}$ but no studies on burnout in autistic people themselves. Two recent clinical articles reference autistic burnout as an issue to be considered, ${ }^{7,8}$ and only a few other recent articles casually mention burnout as a potential consequence of poor social support or masking (camouflaging one's self to conform to social pressures) or include it as research priority. ${ }^{9-12}$

Without research to understand and characterize autistic burnout, it is difficult to provide clinicians, family members, autistic people, and others with effective tools to relieve or prevent it. Although autistic community members may have some shared understanding of the term "autistic burnout," there is as of yet no clear agreed-upon definition of what constitutes autistic burnout. Moreover, it is unclear how well "autistic burnout" may relate to occupational burnout, ${ }^{13}$ where presumably it gets its name. A casual look at some of the potential features of autistic burnout, as described by autistic adults in social media, raises the possibility that it is not a distinct construct, but just a manifestation of clinical depression, which shares features such as fatigue, decreased ability to think or concentrate, or suicidal ideation. ${ }^{14}$

The goal of this study is to begin understanding what the community means by "autistic burnout": what characterizes it, how do people experience it, how might it be distinct (or not) from depression and occupational burnout, how it impacts people's lives, and whether anything can potentially be done to mitigate it.

\section{Methods}

\section{Community-based participatory research approach}

This study was conducted by the Academic Autism Spectrum Partnership in Research and Education (AASPIRE, aaspire.org), a long-running community-based participatory research (CBPR) collaborative comprising autistic people, academic researchers, family members, disability professionals, and clinicians, many of whom identify in more than one of these roles; for example, the principal investigator (PI) and first author for this study (D.M.R.) is both autistic and an academic researcher. ${ }^{15}$ In keeping with the principals of $\mathrm{CBPR}^{16}$ - which support an equitable collaboration between communities and academic scientists to conduct research the community desires-autistic community members directed and participated in all aspects of this study.
AASPIRE meets regularly through text-based chat and email. More information on our processes and guidelines can be found in our participatory methods publications ${ }^{17-20}$ Our community partners identified the study topic, helped shape the grant proposal, and identified the key social media documents analyzed. The PI created first drafts of study materials and the full group discussed and edited the final documents. Although the PI led the data collection and analysis, they returned to the full group for input and interpretation of findings at multiple times: after preliminary analysis, after final analysis, and before the development of this article. The coauthors on this article include both community and academic partners, as well as academic experts in psychiatry (A.R.T.) and organizational psychology (N.A.S.).

The research was approved by Portland State University's Institutional Review Board.

\section{Data sources, setting, and sample}

We compiled data from three sources into a single corpus before analysis.

1. Employment-focused interviews: As part of a separate project on autism and skilled employment, we conducted individual semistructured qualitative interviews with 45 autistic adults about their experiences with work. We recruited a national sample through social media, word of mouth, and our community and professional networks. Participants were U.S. residents, 18 years and older, who self-identified as having a professional diagnosis of an autism spectrum condition (autism spectrum disorder, autistic disorder, Asperger's disorder, pervasive developmental disorder-not otherwise specified), and having received training for a skilled profession. Participants screened into the study through an online or telephone survey and participated in consent and interviewing in their choice of mode: email, telephone, video conference, text-based chat, or, if feasible, in-person. The PI for both studies (D.M.R.) conducted the majority of the interviews, with the minority conducted by a research assistant with experience as an employment support professional under the PI's supervision. Research assistants transcribed and deidentified spoken interviews, and reformatted and deidentified email and text chat interviews. Although we did not ask about autistic burnout, nine participants spontaneously mentioned it by name. We included those nine interviews in this analysis (the remaining interviews did not include information relevant to this study).

2. Burnout-focused interviews: Given the community priority to investigate autistic burnout, we conducted 10 individual semistructured qualitative interviews focused specifically on autistic burnout using the same inclusion/exclusion criteria and procedures as the employment interviews. We purposively sampled for people with lower educational attainment, people who did not have experience with skilled employment, and who identified as male to cover demographics underrepresented in the employment data. The interview guide asked people to talk about their experiences with autistic burnout, how they defined autistic burnout, what they felt characterized it, and advice they had for 
others to prevent it or recover from it. We did not define autistic burnout in recruitment materials or in the interview, to obtain an open-ended understanding of the term from interviewees. The PI conducted the majority of the interviews; research assistant M.S. conducted the remaining interviews under the PI's supervision. The same AASPIRE team developed and implemented both the employment and burnout interviews.

3. Social media documents: Because there has been substantial public conversation about autistic burnout on social media platforms about autistic burnout, we felt it was important to include these conversations in this exploratory study. We compiled a list of 19 sources published between 2005 and 2019 that AASPIRE's community partners felt were key (Table 2) as well as reviewing $\sim 200$ tweets with the hashtag \#AutisticBurnout posted between September 2015 (the earliest tweet with the hashtag) and March 2019. We subjectively selected the five richest (i.e., presented the information in complex and detailed ways) and most representative (i.e., covered the majority of topics found across all sources; many quoted each other) blog posts to include in the final analysis. Social media sources sometimes used the term "autistic regression" interchangeably with "autistic burnout," but, as we were specifically interested in better understanding what people were calling "autistic burnout," we did not actively search on other terms.

Given the similarity in content, we merged social media documents and interviews into a single corpus for analysis.

\section{Qualitative analysis}

We conducted a thematic analysis, ${ }^{21}$ lensed through a critical paradigm. We used a hybrid inductive-deductive approach to analysis. Specifically, we used an inductive approach to characterize participants' experiences, define burnout, and understand how they conceptualized the causes and consequences of burnout. As we were interested in how people defined the term "autistic burnout," rather than looking at what people called something we had already defined, we allowed others to define the term for themselves and did not actively seek alternative terms for similar experiences (though in some cases participants provided alternative language). However, given that depression and occupational burnout are already well described in the literature, we used a deductive approach to distinguish these concepts from participants' descriptions of autistic burnout. We conducted the analysis at both the semantic and latent levels, meaning that we took what people said both at face value and in deeper social context. We used Atlas.ti ${ }^{22}$ software to manage data.

The analysis included four iterations. First, to quickly build an initial code list, the PI (D.M.R.) and a nonautistic research assistant (M.S.) read the 10 burnout interviews and selected 5 representative interviews to share with the academic investigators (C.N., N.A.S., and A.R.T.). Everyone read one-fifth of the social media documents. They created an initial list of inductive codes from those materials. They then added a limited number of deductive codes related to known symptoms of depression and occupational burnout, based on the published literature on each, to explore potential intersections with those constructs.

For the second iteration, they shared the preliminary code list and their impressions of the data with the full AASPIRE CBPR team, who were asked whether they felt the initial codes sounded consistent with their experiences and community conversation (i.e., member checking). Based on this discussion, some codes were rephrased and new codes were added for items community partners felt came up a lot in community discussions but were not in the initial code list. Two of these added codes (physical health conditions, pets as a source of comfort) did not come up in the data. One added code, mental health treatment/therapy as a means of remediating burnout, came up, but in the context of a missing resource, a negative experience, or unrelated to burnout (e.g., for treating a co-occurring mental health condition). Four added codes came up in the data as important constructs but were later collapsed back into higher level themes (executive function difficulties, loss of instrumental activities of daily living, insufficient support for daily living needs, relationship of effort with reward); these four codes all capture important nuances related to the larger themes they ultimately grouped under. Autistic partners felt that the initially identified codes were consistent with community experience and did not recommend removing any.

In the third iteration, two nonautistic undergraduate students (B.L. and A.D.S.), one of whom identifies as having a disability, and M.S. double-coded the corpus using the initial code list, but with freedom to add new themes should they emerge. The three met regularly with each other and with D.M.R. The coders discussed their findings and examined discrepancies in codes; they resolved discrepancies by describing their understanding of the text and discussing until they arrived at codes that fit their consensus interpretation of content. Once completed, D.M.R. collapsed the codes and discussed them with the academic investigators and the full CBPR team for insights and refinements.

For the fourth iteration, D.M.R. reviewed the entire corpus using the collapsed final code set. The findings from this pass were brought to the AASPIRE CBPR team for interpretation.

To help ensure trustworthiness of qualitative findings (the qualitative analogue to validation), we employed multiple coders and peer debriefing at multiple stages, and actively looked for contradictory data. Although there was general agreement on the experience of autistic burnout, details varied widely, as described in the Results section. One interview stood out as being more accurately described by the symptoms of depression. Discussions among coders involved sharing, in addition to academic lenses, reflections, and personal frames as people with a wide variety of lived experience with autism, mental health, and disability.

\section{Results}

The interview participants included 10 females, 7 males, and 4 other gender identifications, ranging in age from 21 to 65 years old. See Table 1 for interview participant demographics; public online data sources are listed in Table 2, with those used in-depth listed first.

When interpreting results, we first assessed the characteristics of autistic burnout; these were chronic exhaustion, loss of skills, and reduced tolerance to stimulus. We then looked 
Table 1. Demographics

\begin{tabular}{|c|c|c|}
\hline & $\begin{array}{c}\text { Burnout } \\
\mathrm{n}=10\end{array}$ & $\begin{array}{c}\text { Employment } \\
\mathrm{n}=9\end{array}$ \\
\hline \multicolumn{3}{|l|}{ Age } \\
\hline Mean (SD) & $41.2(12.2)$ & $33(31.1)$ \\
\hline Range & $24-65$ & $21-65$ \\
\hline \multicolumn{3}{|l|}{ Gender } \\
\hline Female & $4(36 \%)$ & $6(67 \%)$ \\
\hline Male & $7(64 \%)$ & $1(11 \%)$ \\
\hline Other & $0(0 \%)$ & $4(44 \%)$ \\
\hline \multirow[t]{8}{*}{ Location (by U.S. state) } & $\mathrm{AZ}(1)$ & $\mathrm{AZ}(1)$ \\
\hline & AK (1) & CA (1) \\
\hline & LA (1) & $\mathrm{CO}(1)$ \\
\hline & NE (1) & FL (1) \\
\hline & NY (2) & IL (1) \\
\hline & $\mathrm{NC}(1)$ & ME (1) \\
\hline & OR (3) & MA (1) \\
\hline & WA (1) & OR (2) \\
\hline \multicolumn{3}{|l|}{ Race/ethnicity } \\
\hline Non-Hispanic white & $10(100 \%)$ & $6(67 \%)$ \\
\hline \multicolumn{3}{|l|}{ Personal education } \\
\hline High school or less & $3(33 \%)$ & $0(0 \%)$ \\
\hline Associates degree & $1(11 \%)$ & $0(0 \%)$ \\
\hline Bachelors degree & $4(44 \%)$ & $8(89 \%)$ \\
\hline Graduate degree & $1(11 \%)$ & $1(11 \%)$ \\
\hline Disability services use & $5(50 \%)$ & $3(33 \%)$ \\
\hline $\begin{array}{l}\text { Alternative and augmentative } \\
\text { communication use }\end{array}$ & $2(20 \%)$ & $4(44 \%)$ \\
\hline
\end{tabular}

for themes related to attributions of what caused the burnout; these were (1) life stressors (subthemes: masking, expectations, disability management, and life-changes) that lead to (2) cumulative load; (3) barriers to support (subthemes gaslighting/dismissal, poor boundaries/self-advocacy, cannot take a break, lack of external resources/support) that lead to (4) inability to obtain relief; all of which culminate in (5) expectations outweigh ability. We then created a definition of autistic burnout. Lastly, we examined impacts of autistic burnout and potential solutions. Impact themes were health, capacity for independent living, quality of life, and lack of empathy from neurotypical people. Potential solutions are summarized in Table 3.

\section{Characteristics}

The primary characteristics of autistic burnout described by participants were chronic exhaustion, loss of skills, and reduced tolerance to stimulus. These characteristics were described as permeating people's lives and as persisting for an extended time. One participant summarized the experience of autistic burnout: "These periods of burnout caused problems at school and work. I would lose executive function and self-care skills. My capacity for sensory and social overload dwindled to near nothing. I avoided speaking and retreated from socializing. I was spent. I couldn't maintain the facade anymore. I had to stop and pay the price."

\section{Chronic exhaustion}

Participants described an exhaustion of internal resourcesphysical, mental, emotional, or social-as a key feature of their burnout. Participants characterized this directly as feeling "tired" or "exhausted," but typically went on to frame it more specifically as a depletion of energy from overextending themselves in daily life. One person explained:

I've had people say to me many times over the years 'But WHY are you so tired? What have you been doing?' .... The brutal truth is that for an autistic person simply EXISTING in the world is knackering-never mind trying to hold down a job or have any sort of social life. And many of the standard recommendations for 'improving mental health' (such as seeing more people in real life, spending less time on the internet, sitting still and being 'calm') simply make matters worse....We need a LOT of downtime in order to recover from what, for most folk, are the ordinary things of life.

Another participant simply described their experience as, "Having all of your internal resources exhausted beyond measure and being left with no clean-up crew."

\section{Loss of skills}

Participants characterized autistic burnout with the loss of a wide-ranging array of skills, including thinking, remembering, creating, and executing plans, performing activities of daily living and instrumental activities of daily living, using vocational skills in school or work, socializing, regulating emotions, and living independently. They described these as skills they had before the burnout that were lost during burnout, and sometimes did not return to baseline thereafter. For example, one participant shared,

the...way I define burnout...is a regression of skills...for me the really, really scary part of burnout is you don't know whether or not you're gonna get those skills back to the point you had them where you were before [the burnout].

Many narratives listed areas in which skills had been lost: "Decline in executive functioning...loss of life skills, poor memory, problems with speech..."

\section{Reduced tolerance to stimulus}

Participants described being more sensitive than usual to environmental stimuli and less able to tune them out, increased instances of overstimulation, increased meltdowns and shutdowns, and an avoidance of stimulation including social engagements, environments, and activities, even if they were those the participants would otherwise enjoy. One participant described some of their current burnout symptoms as:

VERY low sensory tolerance...-many 'routine' noises have become quite painful, therefore VERY difficult and taxing to access public spaces, shopping/errands, parks, and social gatherings. ...many artificial scents have started to make me MAD, and I've had to make a handful of foods offlimits due to texture.

Another participant related a reduced tolerance to activities which they stated they had previously looked forward to and enjoyed:

I don't survive weddings the same way...I don't enjoy them, there's too much talking - too much sensory, too much interaction, Christmas is hard, like-there's significant 
Table 2. Public Social Media Data Sources

\begin{tabular}{|c|c|c|c|}
\hline Site title & Post title & $U R L$ & Author \\
\hline The Autistic Advocate ${ }^{a}$ & An Autistic Burnout & $\begin{array}{l}\text { http://www.theautisticadvocate.com/2018/ } \\
\text { 05/an-autistic-burnout.html }\end{array}$ & Kieran Rose \\
\hline Musings of an $\mathrm{Aspie}^{\mathrm{a}}$ & $\begin{array}{l}\text { Autistic Regression and } \\
\text { Fluid Adaptation }\end{array}$ & $\begin{array}{l}\text { https://musingsofanaspie.com/2013/12/19/ } \\
\text { autistic-regression-and-fluid-adaptation/ }\end{array}$ & Anonymous \\
\hline Boren Blog ${ }^{a}$ & $\begin{array}{l}\text { Autistic Burnout: } \\
\text { The Cost of Masking } \\
\text { and Passing }\end{array}$ & $\begin{array}{l}\text { https://boren.blog/2017/01/26/autistic-burnout- } \\
\text { the-cost-of-coping-and-passing/ }\end{array}$ & Ryan Boren \\
\hline autistics.org $^{\mathrm{a}}$ & $\begin{array}{l}\text { Help I Seem to Be } \\
\text { Getting More Autistic }\end{array}$ & $\begin{array}{l}\text { http://web.archive.org/web/20061207172126/ } \\
\text { http://www.autistics.org/library/more-autistic } \\
\text {.html }\end{array}$ & Mel Baggs \\
\hline Autisticality $^{\mathrm{a}}$ & Burnout & https://autisticality.com/2015/08/12/burnout/ & Anonymous \\
\hline Twitter & $\begin{array}{l}\text { Hashtag } \\
\text { \#AutisticBurnout }\end{array}$ & $\begin{array}{l}\text { https://twitter.com/hashtag/AutisticBurnout?src= } \\
\text { hash }\end{array}$ & Various \\
\hline Tumblr & Autistic Passing Project & http://autisticpassing.tumblr.com & Various \\
\hline Planet Autism Blog & Aspie Burnout & $\begin{array}{l}\text { https://planetautismblog.wordpress.com/2014/03/ } \\
\text { 05/aspie-burnout/ }\end{array}$ & Anonymous \\
\hline $\begin{array}{l}\text { Judy Endow: Aspects } \\
\text { of Autism } \\
\text { Translated }\end{array}$ & $\begin{array}{l}\text { Autistic Burnout } \\
\text { and Aging }\end{array}$ & $\begin{array}{l}\text { http://www.judyendow.com/autism-and-aging/ } \\
\text { autistic-burnout-and-aging/ }\end{array}$ & Judy Endow \\
\hline $\begin{array}{l}\text { Autism } \\
\text { Empowerment } \\
\text { Radio }\end{array}$ & $\begin{array}{l}\text { Karla Fisher-Autism } \\
\text { Token Theory \& } \\
\text { Autistic Burnout }\end{array}$ & $\begin{array}{l}\text { http://www.blogtalkradio.com/ } \\
\text { autismempowerment/2013/05/03/karla- } \\
\text { fisher-autism-token-theory- } \\
\text { autistic-burnout }\end{array}$ & $\begin{array}{l}\text { Karla Fisher, } \\
\text { Karen } \\
\text { (interviewer) }\end{array}$ \\
\hline $\begin{array}{l}\text { Autism, } \\
\text { Motherhood and } \\
\text { Advocacy }\end{array}$ & $\begin{array}{l}\text { What Is Autistic } \\
\text { Burnout }\end{array}$ & $\begin{array}{l}\text { https://disabilityableismautismandmotherhood } \\
\text {.blogspot.com/2013/06/autistic-burnout.html }\end{array}$ & Kezza \\
\hline Medium & $\begin{array}{l}\text { Today I Learned About } \\
\text { Autistic Burnout }\end{array}$ & $\begin{array}{l}\text { https://medium.com/@ @ixmediocre/today-i- } \\
\text { learned-about-autistic-burnout-c0a154f358a2 }\end{array}$ & Bix \\
\hline The Mighty & $\begin{array}{l}\text { I Am Autistic. } \\
\text { I Am Exhausted. }\end{array}$ & $\begin{array}{l}\text { https://themighty.com/2016/09/experiencing- } \\
\text { burnout-in-the-workplace-as-an-autistic-person/ }\end{array}$ & $\begin{array}{l}\text { Lizzie } \\
\text { Davidson }\end{array}$ \\
\hline $\begin{array}{l}\text { Neurodivergent } \\
\text { Rebel }\end{array}$ & $\begin{array}{l}\text { An Autistic Perspective } \\
\text { \#TakeTheMaskOff- } \\
\text { Masking, Mental } \\
\text { Health, \& Burnout }\end{array}$ & $\begin{array}{l}\text { https://neurodivergentrebel.com/2018/08/10/an- } \\
\text { autistic-perspective-takethemaskoff-masking- } \\
\text { mental-health-burnout/ }\end{array}$ & $\begin{array}{l}\text { Christa } \\
\text { Holmans }\end{array}$ \\
\hline Ollibean & Autistic Burnout & https://ollibean.com/autistic-burnout/ & Judy Endow \\
\hline Autism Wiki & Autistic Regression & https://autism.wikia.org/wiki/Autistic_regression & Anonymous \\
\hline YouTube & $\begin{array}{l}\text { Ask an Autistic \#3- } \\
\text { What is Autistic } \\
\text { Burnout? }\end{array}$ & $\begin{array}{l}\text { https://www.youtube.com/watch?v= } \\
\text { DZwfujkNBGk }\end{array}$ & $\begin{array}{l}\text { Amythest } \\
\text { Schaber }\end{array}$ \\
\hline $\begin{array}{l}\text { KATiE MiA/ } \\
\text { Aghogday: Views } \\
\text { From the Autism } \\
\text { Spectrum and } \\
\text { Beyond }\end{array}$ & $\begin{array}{l}\text { Burnout on the } \\
\text { Autism Spectrum }\end{array}$ & $\begin{array}{l}\text { https://katiemiaaghogday.blogspot.com/2013/04/ } \\
\text { burnout-on-autism-spectrum.html }\end{array}$ & KATiE MiA \\
\hline
\end{tabular}

${ }^{\text {a }}$ Sources used in in-depth analysis.

differences between how I coped with the world before my high school burnout and now, like, I never got back to the point where I was... [Weddings and Christmas] were things I really enjoyed, like being able to see my family and hang out with them and spend time with them... I [still] enjoy them but it's harder to deal with them... Like I get home from Christmas and I spend a week on the couch because I did too much social interaction, too much noise...

\section{Attributions and conceptual model}

The attributions and dynamics described by participants are summarized in our conceptual model in Figure 1.

Attribution themes fell under two broad categories of life stressors that added to the cumulative load experienced by participants, and barriers to support that created an inability to obtain relief from the cumulative load. These two pressures would then contribute to expectations outweighing abilities resulting in autistic burnout. Participants described this process bluntly; for example, "Autistic burnout is a state of physical and mental fatigue, heightened stress, and diminished capacity to manage life skills, sensory input, and/or social interactions, which comes from years of being severely overtaxed by the strain of trying to live up to demands that are out of sync with our needs."

\section{Life stressors}

Participants described a number of life stressors either related to, or exacerbated by, being autistic that contributed to the cumulative load on their energy reserves. By far the most prominent life stressor was masking, or the need to suppress 
Table 3. Potential Solutions for Autistic Burnout

\begin{tabular}{|c|c|c|}
\hline Domain & Strategy & Representative quotations \\
\hline \multirow{6}{*}{$\begin{array}{l}\text { Acceptance } \\
\text { and social } \\
\text { support }\end{array}$} & Individual support & $\begin{array}{l}\text { Have a healthy support system setup of people who will accept you as you are and } \\
\text { not try to change, fix or shame you. }\end{array}$ \\
\hline & & $\begin{array}{l}\text { Having a supportive person or persons who understood my anxieties in their } \\
\text { complexity and helped me face what I could not change by understanding why it } \\
\text { was so difficult for me. Having a loving support system that would respect and } \\
\text { allow me to just be how I was until I could sort out the issues. }\end{array}$ \\
\hline & $\begin{array}{l}\text { Community } \\
\text { support }\end{array}$ & $\begin{array}{l}\text { [My burnout] might have even come sooner than it did had I not been around some } \\
\text { communities of people who were generally more accepting of "quirkiness," and } \\
\text { so provided some periods of time where I likely was needing to mask less, or less } \\
\text { intensely. }\end{array}$ \\
\hline & & $\begin{array}{l}\text { Try to find people who... accept you and I know that's not always, you know, not } \\
\text { always possible but community is out there you know, if the person has a way to } \\
\text { connect to it, the community, that's a good source of support. }\end{array}$ \\
\hline & Peer support & $\begin{array}{l}\text { The writing below [by other autistic people related to burnout] helped me understand } \\
\text { myself. If you are autistic, you will likely see yourself in these perspectives. They } \\
\text { might change your life. }\end{array}$ \\
\hline & & $\begin{array}{l}\text { The biggest thing that has helped me avoid and mitigate it, is learning about myself } \\
\text { and the way I have done that, is by connecting with the Autistic Community. }\end{array}$ \\
\hline \multirow[t]{3}{*}{ Being autistic } & $\begin{array}{l}\text { Attending to } \\
\text { autistic needs }\end{array}$ & $\begin{array}{l}\text { Give yourself a break, go hole up in a cupboard under a blanket for a few hours, } \\
\text { or...run or cycle really, really fast (sometimes the wind rush can literally help } \\
\text { clear away the cobwebs because so much sensory information is cut out). A big } \\
\text { sensory break every few days, or weeks, coupled with smaller sensory breaks } \\
\text { throughout the day could make the world of difference... }\end{array}$ \\
\hline & Unmasking & $\begin{array}{l}\text { The biggest thing of all you can do to prevent, or at least mitigate burnout, is to start } \\
\text { identifying what you do when you Mask and stop. Even just little things like eye } \\
\text { contact, which so many of us do, or at least pretend to do. Allow yourself not to be } \\
\text { sociable if you don't want to be. }\end{array}$ \\
\hline & $\begin{array}{l}\text { Using autistic } \\
\text { strengths }\end{array}$ & $\begin{array}{l}\text { I think [preventing burnout] would be... something around better understanding and } \\
\text { better application of...the sort of natural skills or traits of somebody on the } \\
\text { spectrum. }\end{array}$ \\
\hline \multirow[t]{5}{*}{$\begin{array}{l}\text { Formal } \\
\text { supports }\end{array}$} & $\begin{array}{l}\text { Reasonable } \\
\text { accommodations }\end{array}$ & $\begin{array}{l}\text { I told the [human resources] department that I was autistic and they said, okay well } \\
\text { we'll deal with this... so it was like an } 8 \text { or } 9 \text { page document that we } \\
\text { presented....and at the end of it [they] said.... we're going to give you a permanent } \\
\text { accommodation. The accommodation that they gave me... was the ability to with } \\
\text { short notice take time off without pay.... I have the lights taken out above my } \\
\text { desk, ...now I wear clip on sunglasses....all those things gave me back time gave } \\
\text { me back energy. } \\
\text { Not having my needs be seen as unreasonable or "mental" but getting } \\
\text { accommodations. }\end{array}$ \\
\hline & $\begin{array}{l}\text { Instrumental } \\
\text { support }\end{array}$ & $\begin{array}{l}\text { I wish that I had been able to qualify for like, help cleaning or something for stress at } \\
\text { home. }\end{array}$ \\
\hline & & $\begin{array}{l}\text { Respite services so, so I can get a break from, break from uh, you know, get a break } \\
\text { from the kids when I need it. }\end{array}$ \\
\hline & $\begin{array}{l}\text { Mental health } \\
\text { support }\end{array}$ & $\begin{array}{l}\text { Dealing honestly with scary and difficult emotions might actually be a way to } \\
\text { prevent burnout. By allowing people to complain and be heard the difficulties can } \\
\text { be overcome and the person is actually more likely to be able to put them aside } \\
\text { and work again. }\end{array}$ \\
\hline & & $\begin{array}{l}\text { Okay so to medical professionals I would say um, because depression can be part of } \\
\text { burnout, treat the depression first. }\end{array}$ \\
\hline \multirow[t]{6}{*}{ Reduced load } & Time off/breaks & $\begin{array}{l}\text { On a basic level, allowing periods of withdrawal, or decompression time at the end } \\
\text { of the day, or even throughout the day can make a big difference. }\end{array}$ \\
\hline & & $\begin{array}{l}\text { Take a spiritual retreat [laughs] like that's not a definite way of curing it but that's } \\
\text { the only way I came up with is give yourself a break, withdraw into your own } \\
\text { world and give yourself a break. }\end{array}$ \\
\hline & & The biggest thing of all you can give yourself, or your loved one, is time. \\
\hline & Social withdrawal & $\begin{array}{l}\text { Allow yourself not to be sociable if you don't want to be. Give yourself permission } \\
\text { to duck out of situations you can't cope with instead of pretending you can. }\end{array}$ \\
\hline & & $\begin{array}{l}\text { I have gone through a few distinct periods of burnout and have successfully managed } \\
\text { them by withdrawing from the world as best I could. }\end{array}$ \\
\hline & Reduced activity & $\begin{array}{l}\text { Pulling back from activities, tweaking how much you do of different activities...all } \\
\text { are important. }\end{array}$ \\
\hline
\end{tabular}


TABle 3. (CONTINUED)

\begin{tabular}{|c|c|c|}
\hline Domain & Strategy & Representative quotations \\
\hline \multirow[t]{7}{*}{$\begin{array}{l}\text { Self-advocacy } \\
\text { and health }\end{array}$} & Setting boundaries & $\begin{array}{l}\text { Advice I would give...it's okay to-you know, okay to say no if people.... are asking } \\
\text { things of you that you don't feel like you can handle. }\end{array}$ \\
\hline & & Listen and respect when your boundaries are being crossed. \\
\hline & Asking for help & $\begin{array}{l}\text { I wish I had known much earlier on that there was no shame in needing or requesting } \\
\text { accommodations. If I could redo things, I would likely have tried to acknowledge } \\
\text { the contribution of sensory issues to, say, meltdowns at work and put measures in } \\
\text { place to better manage them. }\end{array}$ \\
\hline & & $\begin{array}{l}\text { Learning to be able to ask and accept help from trusted authorities (Ask and Tell by } \\
\text { Stephen Shore is a good book). }\end{array}$ \\
\hline & & $\begin{array}{l}\text { Asking for help and accepting help is an important skill to succeed through autistic } \\
\text { burnout. }\end{array}$ \\
\hline & Being healthy & $\begin{array}{l}\text { Breathing exercises, regular exercise, doing activities that bring you joy as a way to } \\
\text { decompress. }\end{array}$ \\
\hline & & $\begin{array}{l}\text { Something as simple as petting an animal, meditation, the ability to exercise in short } \\
\text { spurts or do something mindless like watch a funny video or squeeze a stress ball. } \\
\text { That'll help ease the oncoming tension and I can float back down to earth } \\
\text { gracefully. }\end{array}$ \\
\hline \multirow[t]{5}{*}{$\begin{array}{l}\text { Self- } \\
\text { knowledge }\end{array}$} & Early recognition & $\begin{array}{l}\text { Once it happens...it spirals downhill that if you can recognize that you're, you know, } \\
\text { recognize it's happening....and conscious of it then there might be uh, be able to } \\
\text { avoid it. }\end{array}$ \\
\hline & ASD diagnosis & $\begin{array}{l}\text { Asking that question [of what would prevent burnout] now I would say a diagnosis } \\
\text { and help recognizing when I liked doing something. }\end{array}$ \\
\hline & & $\begin{array}{l}\text { What potentially could have helped prevent burnout would have been an earlier } \\
\text { diagnosis, which potentially could have meant less need to camouflage. }\end{array}$ \\
\hline & $\begin{array}{l}\text { Understanding } \\
\text { patterns and } \\
\text { making strategic } \\
\text { decisions }\end{array}$ & $\begin{array}{l}\text { I have learnt to understand the "why" of why I react to certain things in certain } \\
\text { ways, I've learnt to understand "how" to best avoid certain situations or to shield } \\
\text { myself from them with Masking. I've been supported into learning how to Accept } \\
\text { myself and shuck off, to a certain extent what has been thrown at me. }\end{array}$ \\
\hline & & $\begin{array}{l}\text { But by FAR the most crucial dimension of my recovery? I'm recovering my ability } \\
\text { to listen to my own body, after decades of being taught to distrust and override my } \\
\text { very own senses. }\end{array}$ \\
\hline
\end{tabular}

ASD, autism spectrum disorder.

autistic traits or disability, or pretend to be nonautistic. One person explained,

The metaphor I use is that long-term camouflaging and masking leaves behind a kind of psychic plaque in the mental and emotional arteries. Like the buildup of physical plaque over time can result in heart attack or stroke, the buildup of this psychic plaque over time can result in burnout.

Expectations, especially around social pressures, also figured prominently and were interwoven with the masking theme, as masking was often a strategy used to meet family, social, vocational, or other mainstream expectations. Disability management encompassed strategies participants used to compensate for their autistic differences, often in nonaccommodating environments, such as overstimulating workplaces. Life-change stress-those unpredictable life events (e.g., death or moving), as well as more predictable but significant changes (e.g., transition to adulthood)—impacts everyone; however, for autistic people who may struggle with change (more so than the general population), these events
Life Stressors

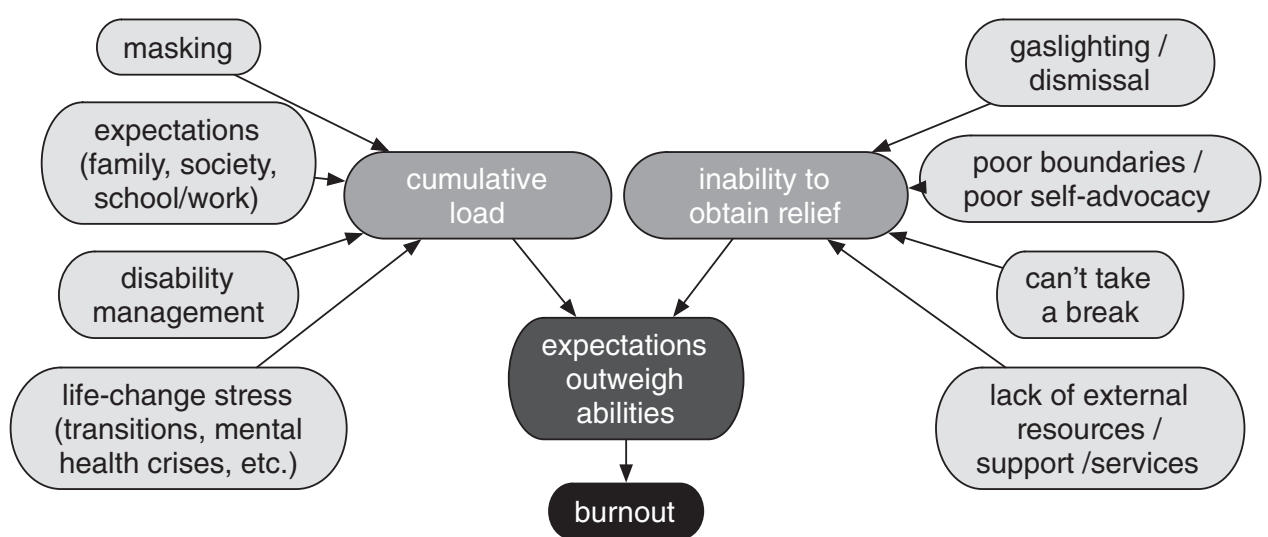

FIG. 1. Autistic burnout conceptual model. 
were characterized by participants as requiring overwhelming amounts of energy to manage, often described as triggering a burnout episode. Many participants reported their first burnout experience occurring around the transition to adulthood. Together, these life stressors added to the cumulative load described in our data.

\section{Barriers to support}

Participants rarely attributed life-stresses alone as causing their burnout but juxtaposed them with an inability to get sufficient relief for those stresses. One of the most prominent subthemes was gaslighting (i.e., making the person question his or her own sense of reality) and dismissal; when people realized their life had become unsustainable and asked for help, they were told their troubles were their own fault or dismissed (e.g., "that happens to everyone"). One participant related:

For a long time I was able to recognize this pattern [of burnout], but I couldn't understand it. I was never able to explain it to other people, because it just sounded like I was being irrationally negative: 'I just have mental breakdowns every few years, so it's bound to happen again soon.' People would just try to reassure me that I was exaggerating or making assumptions. But... I usually turned out to be right.

Participants also related struggling with boundaries-for example, not understanding that they were able to say "no" to tasks or expectations, how to negotiate their own limits with external demands-or understanding how to selfadvocate; for example, " $[\mathrm{I}]$ don't have the words to describe to anybody what's going on or to ask for help." People also talked about not being able to take breaks from particularly stressful aspects of their life, or not having access to external support or resources such as disability services, effective therapy, child care respite, or even a diagnosis; many people related having received their autism diagnosis as a result of losing compensation skills during their burnout. Together, these barriers to support contributed to the inability to obtain relief or recoup the energy debt described in our data.

\section{Expectations outweigh abilities}

This theme appeared more often, and more dominantly, than any others throughout the corpus. Our conceptual model is an attempt to summarize the attributions described by participants and social media writers as funneling into the tipping point where expectations outweighed abilities and autistic burnout occurred. In other words, autistic burnout occurred when the persons felt what they needed to do became more than what was able to do given the combination of their existing resources, the cumulative load they were carrying, and their ability to replenish resources or access support. As one participant explained: “Don't expect us to keep operating at above-peak level. We're like a light sedan car that's driven like a semi diesel hauler...we burn out when over-done."

Participants described how these attributions came together through the expectation/ability mismatch to trigger autistic burnout:

I had this internal switch that would flip under constant, unrelenting stress. At this point, I had felt susceptible to fur- ther belittlement and inquiries from authority. I wanted a place to hide, to recuperate. That is not the way of the world, unfortunately. It's being drained, wounded to such an incredible degree-like your battery has run dry.

\section{Defining autistic burnout}

Based on these findings, and structured similarly (but with different content) to the ICD-11 definition of workplace burnout, ${ }^{23}$ our community-academic team created the following definition of autistic burnout:

Autistic burnout is a syndrome conceptualized as resulting from chronic life stress and a mismatch of expectations and abilities without adequate supports. It is characterized by pervasive, long-term (typically $3+$ months) exhaustion, loss of function, and reduced tolerance to stimulus.

\section{Impacts}

Participants discussed serious impacts of autistic burnout on their health, (mental and physical), capacity for independent living (ability to perform instrumental activities of daily living, sustain employment, sustain important relationships, etc.), and quality of life. They also described a lack of empathy from neurotypical people who did not understand or appreciate the burnout and often made things more difficult. For example, one participant described:

[The burnout] made me feel worthless because I went from being a functional member of society to somebody who wasn't working...but at the same time I wanted to work and my siblings were telling me that I needed to work and...not being able to do that makes you feel like a burden, it makes you feel worthless, it makes you feel-just not as, I don't know, worthy?

Of particular note, multiple participants discussed how their experience of burnout led to self-injury, suicidal thoughts, or suicide attempts.

[My situation] became way too much. After I [quit my job], I found it increasingly difficult to speak to people I didn't know and became very depressed. I was told that this was considered autistic regression by a therapist. I was unable to work for several years after this experience and attempted suicide/spent time in the mental hospital before being able to get my life back in order.

In another person's words, "I did not want to die, I've never wanted to die...I needed to remove myself from the environment and take myself elsewhere... But the only way I knew how to do that was to die. So I tried.'

\section{Potential solutions}

Although some of these impacts are dire, participants also were able to articulate potential solutions to relieve or prevent autistic burnout. Table 3 presents some key solutions noted by participants to recover from, or prevent, autistic burnout. Some notable solutions are related to being understood and accepted by others, having sufficient ability to relax, and doing things in more naturally autistic ways, including less masking. 


\section{Discussion}

Our study found that "autistic burnout" is a term used consistently by autistic adults to describe their experience of a long-lasting pervasive state of exhaustion, loss of function, and reduced tolerance to stimulus that is conceptualized as resulting from chronic life stress and a mismatch of expectations and abilities without adequate supports. This experience was generally ill-understood by others and often dismissed, which made seeking help or relief difficult, and eroded self-esteem and self-efficacy. It had substantial impact on people's lives, often resulting in loss of vocation, health, and quality of life, and, at times, leading to suicidal behavior. Despite these distressing findings, participants also articulated ways they had gotten themselves out of burnout, and ideas for how to prevent it. This suggests potential to develop individual and systems-level interventions for prevention and recovery.

Although autistic burnout has not been described in the literature, workplace burnout is well researched. The literature on occupational burnout describes a response to chronic stress in an employment situation, including "overwhelming exhaustion; feelings of cynicism and detachment from the job; and a sense of ineffectiveness and failure", 13 with resulting impairment of both personal and interpersonal functioning including depression. ${ }^{24}$ Researchers disagree on the validity of existing burnout measures ${ }^{25}$ and some argue for allowing participants to define burnout for themselves. ${ }^{26}$ As with autistic burnout, systematic research on workplace burnout followed the vernacular popularization of the term among those who had experienced adverse impacts from stressful work situations where demands outpace available resources to meet those demands, specifically in the fields of human services, education, and health care. ${ }^{13}$

Descriptions of autistic burnout share some superficial similarities to depression; however, we strongly believe it is a distinct condition. Some key characteristics of depression, such as anhedonia and sleep problems, were outliers in our data, and some participants who had a co-occurring depressive disorder diagnosis made an explicit note of how their experience of autistic burnout was different from an episode of depression. Several felt that autistic burnout contributed to subsequent onset or relapse of depression.

Some autistic adults in our data referred to their burnout as "autistic regression." The term is most commonly used to describe children who appear to lose skills and "become", autistic after seeming to develop normally ${ }^{27,28}$; however, the community of autistic adults and others have used it to describe periods of skills loss, while also finding the term problematic and inappropriate since it is applied to children and implies going backwards. ${ }^{29}$ We advise using "autistic burnout" for the phenomena described in our data. Unlike autistic regression, loss of skills is only one component of burnout.

A new literature has been emerging on masking in autism as a common if costly strategy to avoid the stigma, discrimination, lack of accommodation, and belittling often experienced by autistic people. Multiple studies have found increased masking associated with increased depression, anxiety, and other mental health challenges. ${ }^{30-32}$ A recent study found correlations between increased masking and suicidality. ${ }^{33}$ Although masking comes with social and other rewards, it also comes with deep risks. A recent qualitative study delves deeply into reasons for, and consequences of, masking, which matched themes from our data (e.g., reasons like social pressure and the need to meet expectations; consequences like exhaustion and hiding one's true self). ${ }^{34}$ Additional qualitative work supports these connections and further found them to be true regardless of whether or not a self-identified autistic person has a formal diagnosis. ${ }^{9}$ Although masking is only one component in our findings, existing literature supports and reinforces the narratives of masking's role as a contributor to the cascade of factors that result in autistic burnout. Further interaction with masking research could be beneficial to understanding autistic burnout.

The potential link between autistic burnout and suicidality deserves special mention. Autistic adults have higher rates of suicidal ideation and suicidal behaviors than the general population. ${ }^{35}$ Recent survey research suggests that both autism-specific and nonspecific factors may contribute to heightened suicide risk. ${ }^{33}$ Our qualitative data point to autistic burnout fitting within this framework. Some life stressors and barriers to support that comprise autistic burnout are relatively specific to the autistic experience (for instance, overload from sensory stimuli). Others are relatively nonspecific but may occur more frequently and with more severity for autistic adults than the general population (for instance, lack of resources and stress from life transitions). Suicide risk assessment and management of suicide risk may be integrated into any intervention related to autistic burnout.

This study has several limitations. It is a small qualitative study from a convenience sample and does not represent the full diversity of the autistic adult population. Although we were able to bring in more perspectives by using three data sources, future work would benefit from interviewing a wider range of participants, especially those who are not white, who have higher support needs, who are nonverbal, who are unable to "pass" for nonautistic, who have either very high or very low educational attainment, and who experience multiple marginalized identities. Although we specifically focused on autistic burnout, it is possible that people with other disabilities and people with chronic illnesses may experience burnout. Having only collected data from autistic adults, we cannot compare autistic burnout with burnout that might be experienced by other populations; however, this could be a fruitful area for further investigation. Despite these limitations, we feel our data display authenticity in that they represent a range of realities, provide a more sophisticated understanding of the phenomena of interest, encompass contradictory viewpoints within an otherwise theme-saturated corpus, and suggest potential actions.

AASPIRE is continuing to examine autistic burnout. The findings reported here are from the first phase of a two-phase project, the second aim of which is to begin developing a measure of autistic burnout. In addition to our study-which was focused on autism and the term "autistic burnout" due to our focus as a CBPR collaborative and the nature of the funding we received-we strongly feel that further research is needed to examine whether this may be a generalized "disability burnout" —or an even more generalized burnout experienced by others who experience similar dynamics of marginalization and burden in their lives. 
As, to our knowledge, the first empirical study to examine autistic burnout, this study has numerous implications. Most notably, autistic burnout appears to be a definable phenomenon that substantially impacts people's lives and needs urgent attention. Participants described how engagement with the autistic adult community to name and validate their experience helped them recover. Thus, it may be important to educate autistic adults about autistic burnout. For therapists and other practitioners, these findings have implications related to recognizing autistic burnout in clients, validating their experience, and offering strategies for relief. Our data underscores the potential dangers of teaching autistic people to mask or suppress their autistic traits, or to push themselves to meet mainstream expectations. In addition, suicide prevention programs need to consider the potential role of burnout, as programs focused primarily on recognizing and treating depression or increasing social support may not adequately address an important pathway to suicide. Systems-level implications include reducing discrimination and stigma related to autism and disability, and working toward accommodations and acceptance to decrease the risk of autistic burnout. Lastly, more research is needed to further understand and measure autistic burnout, as well as to develop and test ways to relieve and prevent it.

\section{Authorship Confirmation Statement}

Dr. Dora M. Raymaker led the study design, data collection, and data analysis, and wrote the majority of the article. Drs. Alan R. Teo and Nicole A. Steckler contributed to the study design and data analysis and wrote portions of the article. Brandy Lentz, Mirah Scharer, and Austin Delos Santos performed the majority of the qualitative coding and contributed to the analysis. Ms. Scharer also helped with data collection. Dr. Steven K. Kapp, Morrigan Hunter, and Andee Joyce served as AASPIRE community partners, contributing to study design, the development of all research materials, selection of online data sources, recruitment, code and theme development, and interpretation of findings. Dr. Christina Nicolaidis provided mentorship through all phases of the project, contributed to study design and data analysis, and wrote portions of the article. All coauthors revised the article for critical content and approved the final version. This article has been submitted solely to this journal and is not published elsewhere.

\section{Acknowledgments}

We thank the full AASPIRE team, as well as all of our research participants, without whom this study would not have been possible.

\section{Author Disclosure Statement}

No competing financial interests exist.

\section{Funding Information}

This research supported by National Institute of Mental Health award number 1R21MH112038, and by Oregon Health \& Science University/Portland State University Collaboration Seed funding. The content is the responsibility of the authors and does not necessarily represent the views of NIMH, OHSU, or PSU.

\section{References}

1. Rose K. An autistic burnout. In: The Autistic Advocate: Autistic People Have a Voice. Vol. 2018. https://theautistic advocate.com/2018/05/an-autistic-burnout/ (accessed April 3, 2020).

2. Boren R. Autistic burnout: The Cost of Coping and Passing. In: Ryan Boren: Non-compliant neurodivergent. Vol. 2018. 2017; https://boren.blog/2017/01/26/autistic-burnout-thecost-of-coping-and-passing/ (accessed April 3, 2020).

3. Galam E, Vauloup Soupault C, Bunge L, Buffel du Vaure C, Boujut E, Jaury P. 'Intern life': A longitudinal study of burnout, empathy, and coping strategies used by French GPs in training. BJGP Open. 2017;1(2):bjgpopen17X 100773.

4. Gerain P, Zech E. does informal caregiving lead to parental burnout? Comparing parents having (or not) children with mental and physical issues. Front Psychol. 2018;9: 884.

5. Merrick AD, Grieve A, Cogan N. Psychological impacts of challenging behaviour and motivational orientation in staff supporting individuals with autistic spectrum conditions. Autism. 2017;21(7):872-880.

6. Reiter S, Vitani T. Inclusion of pupils with autism: The effect of an intervention program on the regular pupils' burnout, attitudes and quality of mediation. Autism. 2007; 11(4):321-333.

7. Zener D. Helping autistic women thrive. Adv Autism. 2019; 5(3):143-156.

8. Zener D. Journey to diagnosis for women with autism. $A d v$ Autism. 2019;5(1):2-13.

9. Livingston LA, Shah P, Happe F. Compensatory strategies below the behavioural surface in autism: A qualitative study. Lancet Psychiatry. 2019;6(9):766-777.

10. Frost KM, Bailey KM, Ingersoll BR. "I just want them to see me as... me": Identity, community, and disclosure practices among college students on the autism spectrum. Autism Adulthood. 2019;1(4):268-275.

11. Raymaker DM. Reclaiming research for the autistic adult community. Autism Adulthood. 2019;1(3):160-161.

12. Mandy W. Social camouflaging in autism: Is it time to lose the mask? Autism. 2019;23(8):1879-1881.

13. Maslach C. A multidimensional theory of burnout. In: Cooper CL, ed. Theories of Organizational Stress. Oxford University Press; 1998;68-85.

14. Otte C, Gold SM, Penninx BW, et al. Major depressive disorder. Nat Rev Dis Primers. 2016;2:16065.

15. Raymaker DM. Reflections of a community based participatory researcher from the intersection of disability advocacy, engineering, and the academy. Action Res (Lond). 2017;15(3):258-275.

16. Israel BA, Schulz A, Parker E, Becker A, Allen AI, Guzman J. Critical issues in developing and following community based participatory research principles. In: Minkler M, and Wallerstein, N, eds. Community Based Participatory Research for Health. San Fransisco, CA: Jossey-Bass; 2003;53-76.

17. Nicolaidis C, Raymaker DM, McDonald KE, et al. Collaboration strategies in non-traditional CBPR partnerships: Lessons from an academic-community partnership with autistic self-advocates. Prog Community Health Partnersh. 2011;5(2):143-150.

18. Raymaker DM. Intersections of critical systems thinking and community based participatory research: A learning organization example with the autistic community. Syst Pract Action Res. 2016;29(5):405-423. 
19. Nicolaidis C, Raymaker D, Kapp SK, et al. The AASPIRE practice-based guidelines for the inclusion of autistic adults in research as co-researchers and study participants. Autism. 2019;23(8):2007-2019.

20. Nicolaidis C, Raymaker DM, McDonald K, et al. Creating accessible survey instruments for use with autistic adults and people with intellectual disability: Lessons learned and recommendations. Autism Adulthood. 2020;2(1).

21. Braun V, Clarke V. Using thematic analysis in psychology. Qual Res Psychol. 2006;3(2):77-101.

22. ATLAS.ti. ATLAS.ti: Qualitative data analysis. https:// atlasti.com. Published 2018. Accessed October 14, 2018.

23. World Health Organization. International classification of diseases for mortality and morbidity statistics. https://icd .who.int/browse11/1-m/en. Published 2018. Accessed October 18, 2019.

24. Sargent MC, Sotile W, Sotile MO, Rubash H, Barrack RL. Quality of life during orthopaedic training and academic practice. Part 1: Orthopaedic surgery residents and faculty. J Bone Joint Surg Am. 2009;91(10):2395-2405.

25. Qiao H, Schaufeli WB. The convergent validity of four burnout measures in a Chinese sample: A confirmatory factor-analytic approach. Appl Psychol. 2011;60(1):87-111.

26. Dolan ED, Mohr D, Lempa M, et al. Using a single item to measure burnout in primary care staff: A psychometric evaluation. J Gen Intern Med. 2015;30(5):582-587.

27. Zhang Y, Xu Q, Liu J, Li S-C, Xu X. risk factors for autistic regression: Results of an ambispective cohort study. J Child Neurol. 2012;27(8):975-981.

28. Werner E, Dawson G. Validation of the phenomenon of autistic regression using home videotapes. Arch Gen Psychiatry. 2005;62(8):889-895.

29. Baggs M. Help! I seem to be getting more autistic! http:// web.archive.org/web/20061207172126/http://www.autistics .org/library/more-autistic.html. Published 2005. Accessed October 11, 2019.

30. Cage E, Di Monaco J, Newell V. Experiences of autism acceptance and mental health in autistic adults. $J$ Autism Dev Disord. 2018;48(2):473-484.

31. Cage E, Troxell-Whitman Z. Understanding the reasons, contexts and costs of camouflaging for autistic adults. J Autism Dev Disord. 2019;49(5):1899-1911.

32. Lai M-C, Lombardo MV, Ruigrok ANV, et al. Quantifying and exploring camouflaging in men and women with autism. Autism. 2016;21(6):690-702.

33. Cassidy S, Bradley L, Shaw R, Baron-Cohen S. Risk markers for suicidality in autistic adults. Mol Autism. 2018; 9(42):1-14.

34. Hull L, Petrides KV, Allison C, et al. "Putting on my best normal": Social camouflaging in adults with autism spectrum conditions. J Autism Dev Disord. 2017;47(8):25192534.

35. Cassidy S, Bradley P, Robinson J, Allison C, McHugh M, Baron-Cohen S. Suicidal ideation and suicide plans or attempts in adults with Asperger's syndrome attending a specialist diagnostic clinic: A clinical cohort study. Lancet Psychiatry. 2014;1(2):142-147.

Address correspondence to:

Dora M. Raymaker, PhD

Regional Research Institute School of Social Work

Portland State University

1600 SW 4th Avenue, Suite 900

Portland, OR 97201

USA

E-mail: draymake@pdx.edu 